\title{
Medical conditions and treatment in a transit camp in Serbia for Syrian, Afghani, and Iraqi migrants
}

\author{
Einav Levy ${ }^{1,2,6^{*}}$, Michael Alkan ${ }^{3}$, Sharon Shaul ${ }^{4}$ and Yori Gidron ${ }^{5}$
}

\begin{abstract}
Thousands of migrants arrived in Europe via the Balkan route, many with various health conditions. The camp of Preševo, Serbia, close to the Macedonian border, was established by the Serbian government and run by the United Nations High Commissioner. The camp was wstablished for Refugees (UNHCR) late in 2015 as a registration and a transfer camp for refugees traveling through the Balkans on their way from the Near East to Western Europe. Refugees stayed at the camp for several hours or a day. NATAN, an Israeli non-governmental volunteer organization, in collaboration with HUMEDICA, a German organization, established a clinic at the camp, staffed by Israeli and German personnel. The Israeli team consisted of a doctor, nurse, and social worker, at least one of whom spoke Arabic. The language barrier was bridged through the fact that Arabic is commonly spoken in Israel, and more than half of the volunteers were Palestinian-Israelis. As for the Farsi language, we were helped by interpreters from the Department of Languages in the University of Belgrade. This report contains data on 2136 consecutive clients visiting the clinic between December 2015 and February 2016.

The report focuses on the three most frequent major countries of origin, Syria (51\%), Iraq (18\%), and Afghanistan (31\%). Analysis of the age distribution revealed that $36 \%$ were under 18 years of age, while only $5 \%$ were above the age of 60 . Male gender was predominant. Infections were the most common diagnosis (61\%) followed by pain in various body parts (13\%). Antibiotics were prescribed in $47.6 \%$ of the infections. Most of the visits were for minor illnesses, with very few cases of chronic diseases such as diabetes (28 visits) or hypertension (17 visits). We provide the demographic correlates of migrants' health conditions and discuss the findings in light of past studies and the context of the present sample of migrants.
\end{abstract}

Keywords: Migration, Refugees, Medicine, Camp, Humanitarian aid, Middle East

\section{Introduction}

The ongoing current crisis in the Middle East, for the period since the beginning of the civil war in Syria on 2011, is the cause of one of the largest migrations in recent history from the Near East to Northern Europe. One of the routes defined by the United Nations High Commissioner for Refugees (UNHCR) has been termed "The Balkan Route," passing from Turkey through Greece to the countries of former Yugoslavia (UNHCR.i.e., 2001). According to the UNHCR, between December 2015 and February 2016, 172,365 migrants had passed through the

\footnotetext{
*Correspondence: levygaea@gmail.com

${ }^{1}$ The Free University of Brussels, (VUB), Brussels, Belgium

${ }^{2}$ The Israeli School of Humanitarian Aid, Tel Aviv, Israel

Full list of author information is available at the end of the article
}

Balkan route. The clinic described in this paper was active throughout this period. Assessing health problems of refugees attending clinics at a refugee camp is important, as it can influence prioritization of resources (Bradby et al. 2015) and thus could reduce morbidity and mortality. The profile of medical conditions among refugees is influenced by the health conditions and risks in their country of origin (e.g., hygiene, diet, genetic susceptibility), whether they experienced war-related injuries and atrocities, healthconditions acquired during their voyage, and diseases acquired in the camp. Other factors such as age, gender, and lifestyle also contribute to the health conditions seen among refugees. For example, in an older study on Kampuchean refugees, malaria and fever were the most prevalent health problems and mortality was most 
prevalent among children under age four (Glass et al. 1980). A study on residents of refugee camps who survived war found that tuberculosis, nutritional deficiency, intestinal parasites, chronic hepatitis $\mathrm{B}$, and depression were the major observed problems (Ackerman 1997). Among 4710 refugees treated after the South Asia tsunami, respiratory problems and skin problems were prevalent, while diarrhea was not common, due to provision of potable water (Lim et al. 2005). According to Doocy et al. (2015), 1550 Syrian households of refugees residing outside camps in Jordan reported the following leading chronic diseases among their care seekers, data relate to households: hypertension (9.7\%), arthritis (6.8\%), diabetes (5.3\%), cardiovascular diseases (3.7\%), and respiratory diseases (3.1\%). Cetorelli et al. (2017) conducted among 1300 households in settled camps in Kurdistan (Northern Iraq) reported hypertension (19.4\%), musculoskeletal conditions (13.5\%), diabetes (9.7\%), and cardiovascular diseases (6.3\%) among 8360 of the household members. Studies on morbidity of refugees along the Balkan route indicate that infectious diseases are the most common ailment among the refugees (Ozaras et al. 2016b; Ozaras et al. 2016a). This study describes the prevalence of health conditions and treatments as well as the demographic correlates (age, gender, country of origin) of clients arriving at one clinic on the Balkan route within a transit camp.

Other studies have described health issues before migration or after they have settled down. Our data relate to interim period of migration, and elucidates their priorities while in transit. The main goal of the migrants at this critical stage is moving towards the target rather than worrying about their health.

\section{Methods}

Participants: a total of 3723 migrants had visited our clinic in a transit UNHCR camp in Preševo, Serbia, near Macedonia, between December 2015 and February 2016. The UNHCR data was used as a surrogate marker for entry to the camp, as direct data was not available. The correlation between the number of clients in the clinic and the number of migrants on the Balkan route over different periods was significant and positive: $r=0.343$, $p<0.005$. This suggests that the quantity of migrants arriving at our clinic may reflect those of the migrants entering the camp in general. The camp was created for registration, humanitarian aid, and assistance in traveling North. The migrants stayed at the camp for several hours up to a few days. The clinic was established by an Israeli non-governmental organization (NGO), NATAN (Natan-iha.org, 2018), and HUMEDICA, a German NGO (Humedica.org, 2016). The clinic provided primary care and was run by a physician, a nurse, and a social worker, of whom at least one of them spoke Arabic. The clinic followed a general procedure of identifying the patient and obtaining general information (age, country of origin, gender), performing diagnosis and providing treatment according to the available resources. A major constrain was the distance to the closest referral center, which resulted in repeated refusals of patients to be sent to this hospital. A process which was hindering their progress. This limited our ability to render appropriate diagnosis and treatment. In the few cases that were referred, administrative obstacles had to be overcome. As for Farsi language, we were helped by interpreters from the Department of Languages of the University of Belgrade. Patients were registered by name, self-reported country of origin, gender, age, main diagnosis, and treatment. Each line of the reporting sheet represented one patient. The data on the sheet were collected on an excel sheet, for the purpose of the daily running of the clinic rather than for research purposes. Of the 3723 patients, complete data were available for 1524 patients, due to time, technical, and logistical constrains. More than $95 \%$ of these had relatively complete data, except for the variable of country of origin that was missing for $28.6 \%$ of the patients. The diagnoses were established by a relatively large number of volunteer doctors (12 in 3 months) and were based on history taking and physical examination only. No informed consent was obtained because all of the presented data were collected as part of the clinic's routine clinical work and registration, rather than for research purposes.

\section{Diagnosis and treatment}

The equipment at the clinic was basic and included a sphygmomanometer, a glucometer, a pulse oximeter, and a portable gynecological ultrasound machine (alongside with other routinely used instruments such as thermometers, urine test sticks, and stethoscope). To include a smaller but comprehensive list of diagnoses, these were grouped into eight categories: chronic diseases, pain, infection, trauma, obstetrics and gynecology, dental problems, "others" (e.g., post-traumatic stress disorder (PTSD), $0.3 \%$ ) and "no disease." Diagnoses were made according to the history taking and physical examination. In very few cases, laboratory or imaging results were available.

Treatment was basic due to limited budget, time, space, personnel, equipment, and medications. To have a manageable and meaningful list of treatments, the following treatment categories were used: antibiotics, analgesics, external treatment (e.g., creams), and others. Two hundred and twenty-eight patients received no treatment. When antibiotics were given, a dose sufficient for the full course of treatment was dispensed. Analgesics and other medications were given as needed. Injuries were treated by disinfectants and bandages, while plaster casts were applied to fractures.

\section{Statistical analysis}

We categorized participants according to country of origin, age groups, and gender, as well as by diagnostic and 
treatment groups. Beyond descriptive statistics (means, standard deviations, and percentages), we used chi square tests, $t$ tests, and analyses of variance (ANOVA) with SPSS 22.0, to examine the associations between diagnosis and treatment with age, gender, and country of origin. Some of the analyses focused on the five most prevalent diagnostic groups, to gain more statistical power. Due to differing numbers of missing data among the variables, the total sample is not consistent in different analyses. However, rather than using the smallest number of participants common to all variables, we decided to use the largest available numbers to make the analysis more representative for our conclusions. Concerning the variable of country of origin, this information was missing for 611 participants. We further removed from the analysis 87 participants who were from countries other than the three main countries of refugees (Syria, Iraq, and Afghanistan). Thus, all analyses concerning country of origin focused on the three main countries $(n=1524)$.

\section{Results}

\section{Descriptive statistics}

Table 1 presents the percentages of people within categories as a function of the main variables in the present study. The participants' age was divided into four groups: infants
( $\leq 1$ ), pre-school (Bradby et al. 2015; Glass et al. 1980; Ackerman 1997; Lim et al. 2005; Doocy et al. 2015), schoolage (Cetorelli et al. 2017; Ozaras et al. 2016b; Ozaras et al. 2016a; Natan-iha.org, 2018; Humedica.org, 2016; http:// data2.unhcr.org/en/situations/mediterranean, 2018; Gulacti et al. 2017; van Berlaer et al. 2016; Sharara and Kanj 2014; Alpak et al. 2015; Kimerling et al. 2006) and adults ( $\geq 18)$ years. There were too few elderly to include as a separate age group (Only 68 patients, 3.2\%, were above the age of 60 years). The mean (SD) age of the entire sample was 22.6 (15.88) years. The most prevalent diagnosis was infections followed by pain. The most prevalent treatment was analgesics, and these were prescribed for pain and fever (Table 1).

\section{Inferential statistics}

The following section presents the analyses testing the associations between diagnosis and treatment with age, gender, and country of origin.

Concerning specific types of diagnoses and age, when examining the diagnosis of pain, we excluded infants due to the difficulty in verifying pain with the limited communication in such age. Pain was diagnosed among pre-school children (5\%), which was considerably lower compared with school children (10.6\%) and adults (18.1\%). These percentages were significantly different

Table 1 Means and standard deviations (SD) and percentages of main study variables in Afghans, Syrians and Iraqis Groups

\begin{tabular}{|c|c|c|c|c|}
\hline \multirow[t]{2}{*}{ Origin } & $n=401$ & $n=746$ & $n=290$ & 1524 \\
\hline & Afghans & Syrians & Iraqis & Total \\
\hline Variable & Mean (SD) & Mean (SD) & Mean (SD) & \\
\hline Age & $20.56(13.66)$ & $23.15(16.81)$ & 23.06(16.49) & \\
\hline Gender (female) (\%) & $40.4 \%$ & $43.3 \%$ & $44.5 \%$ & \\
\hline (Male) (\%) & $59.6 \%$ & $56.7 \%$ & $55.5 \%$ & \\
\hline \multicolumn{5}{|c|}{ Diagnosis (\% of group) } \\
\hline Infections & $273(68 \%)$ & $432(58 \%)$ & $175(60 \%)$ & $880(61 \%)$ \\
\hline Pain & $49(12 \%)$ & $98(13 \%)$ & $41(14 \%)$ & $188(13 \%)$ \\
\hline Chronic D* & $16(4 \%)$ & $44(6 \%)$ & $16(5.5 \%)$ & $76(5.3 \%)$ \\
\hline Trauma & $32(8 \%)$ & 79 (10.6\%) & $32(11 \%)$ & $143(10 \%)$ \\
\hline OBGYN** & $4(1 \%)$ & $17(2.3 \%)$ & $5(1.7 \%)$ & $26(1.8 \%)$ \\
\hline Dental & $10(2.5 \%)$ & $28(4 \%)$ & $13(4.5 \%)$ & $51(3.6 \%)$ \\
\hline No disease & $2(0.5 \%)$ & $2(0.3 \%)$ & $1(0.3 \%)$ & $5(0.3 \%)$ \\
\hline Other & $15(3.7 \%)$ & $45(6 \%)$ & $7(2.4 \%)$ & $67(4.7 \%)$ \\
\hline \multicolumn{5}{|l|}{ Treatment (\%) } \\
\hline Antibiotics & $68(17.3 \%)$ & $91(12.6 \%)$ & $57(20.3 \%)$ & $216(15.5 \%)$ \\
\hline Analgesics & $120(30.5 \%)$ & $231(32 \%)$ & $88(31 \%)$ & 439 (31.4\%) \\
\hline External & $87(22.1 \%)$ & 155 (21.5\%) & $61(21.7 \%)$ & $303(21.7 \%)$ \\
\hline Other & $52(13.2 \%)$ & 114 (15.8\%) & 44 (15.7\%) & $210(15 \%)$ \\
\hline None & 67 (17\%) & 130 (18\%) & 31 (11\%) & $228(16.3 \%)$ \\
\hline
\end{tabular}

Note: The number do not always add up equally due to differential missing values on different variables *Chronic $\mathrm{D}=$ Chronic Disease

** OBGYN= Obsestrics and Gynecology 
when comparing the distribution of clients with and without pain between these age groups $\left(X^{2}(2)=38.76\right.$, $p<0.001)$.

There was significant association between gender and the sub-diagnoses of infections $\left(X^{2}(2)=8.91 ; p<0.05\right)$. Inspecting the sub-diagnoses by gender, revealed that while in males, $86.4 \%$ had URTI and $11.4 \%$ had other infections, in females, $78.6 \%$ had URTI while $18.6 \%$ had other infections. There was a significant difference between country groups and age $(\mathrm{F}(2,1422)=3.70$, $p<0.05)$. Following this cumulative effect, we found that Afghans had significantly lower age compared to the combined age of Syrians and Iraqis $(\mathrm{t}(1422)=2.61$; $p<0.01$ ).

There was no significant difference between countries in gender distribution $\left(X^{2}(2)=1.37 ; p>0.05\right)$. However, countries differed significantly in distribution of treatments $\left(X^{2}(8)=16.51 ; p<0.05\right)$. Relatively, more Iraqis received antibiotics but less of them received no treatment that Syrian or Afghans.

There was a significant association between gender and diagnosis. $\left(X^{2}(7)=62.89, p<0.001\right)$. More men were diagnosed with physical trauma (64.2\%) than women $(35.8 \%$, $Z=3.46, p<0.001)$. The latter cannot be attributed to differences in diagnosing pain, since within the diagnosis of pain, there were no gender differences.

Since infections were the largest diagnostic group, we ran further sub-analyses within the infections category by dividing them into three groups: (1) gastrointestinal infections (GII), (2) respiratory tract infections (RTI), and (3) others See Table 2. Countries were not

Table 2 Distribution of sub-groups with infections, by gender, age, and origin

\begin{tabular}{|c|c|c|c|c|}
\hline \multicolumn{5}{|l|}{ Variable } \\
\hline Diagnostic group & $\mathrm{G} \|^{*}$ & $\left.(U) R T\right|^{* *}$ & Others & Total \\
\hline \multicolumn{5}{|l|}{ Gender } \\
\hline Men & $20(4.1 \%)$ & $416(84.6 \%)$ & $56(11.4 \%)$ & 492 (100\%) \\
\hline Women & $9(2.8 \%)$ & $253(78.6 \%)$ & 60 (18.6\%) & $322(100 \%)$ \\
\hline \multicolumn{5}{|l|}{ Origin } \\
\hline Afghanistan & 7 (24.1\%) & $214(31.3 \%)$ & 38 (31.7\%) & \\
\hline Iraq & $9(31 \%)$ & 135 (19.8\%) & $24(20 \%)$ & \\
\hline Syria & $13(44.8 \%)$ & $334(48.9 \%)$ & $58(48.3 \%)$ & \\
\hline Total & $29(100 \%)$ & $683(100 \%)$ & $120(100 \%)$ & \\
\hline \multicolumn{5}{|l|}{ Age } \\
\hline Infants $(\leq 1)$ & 7 (24.1\%) & $60(8.8 \%)$ & $11(9.2 \%)$ & \\
\hline Pre-school (2-6) & 7 (24.1\%) & $121(17.8 \%)$ & 30 (25.2\%) & \\
\hline School (7-17) & $5(17.2 \%)$ & $128(18.9 \%)$ & $22(18.5 \%)$ & \\
\hline Adults ( $\geq 18$ ) & 10 (34.5\%) & $370(54.5 \%)$ & $56(47.1 \%)$ & \\
\hline Total: & $29(100 \%)$ & 679 (100\%) & 119 (100\%) & \\
\hline
\end{tabular}

${ }^{*}$ GII = gastro-intestinal infections

${ }^{*} R T I=$ respiratory tract infections significantly different in proportions of sub-diagnoses of infectious diseases $\left(X^{2}(4)=2.33 ; p>0.05\right.$. Yet, there was a significant association between age categories and sub-diagnoses of infections $\left(X^{2}(6)=13.20, p<0.05\right.$. The proportion of infants having GII and other infectious problems was relatively high compared to the other age groups. In contrast, the older age groups had higher rates of RTI than infants. Finally, we found a significant association between gender and sub-diagnosis of infections $\left(X^{2}(2)=9.21, p=0.01\right)$. While a higher proportion of men had RTI than women, an equal proportion of men and women had GII.

The frequency of chronic diseases $(\underline{n}=79,5.2 \%)$ was not different when related to the country of origin $(p>0.05)$ (Table 2).

\section{Discussion}

The purpose of this study was to describe the prevalence and demographic correlates of health conditions and treatments among refugees arriving at a field clinic. Most of our patients were young Syrians (mean age 23.14 years), probably since young people have the physical strength to endure the migration journey. In comparison to previous studies, our clinic treated a large percentage of women $(45 \%)$ and children $(<18$ years) $(36 \%)$. The explanation for this fact may be the late timing of our team's clinical mission (December 2015 to May 2016). In the beginning of the refugee crisis, mainly adult men were the ones who arrived in Europe (http://data2.unhcr.org/en/ situations/mediterranean, 2018).

In this study, infectious diseases were the most common diagnosis, mainly gastrointestinal and respiratory (80\%). In a paper describing Emergency Department visits of Syrian refugees in Turkey, URTI was found to be the most prevalent diagnosis (47.3\%) (Gulacti et al. 2017). Another paper, which described the morbidity among refugees after arriving Western Europe (van Berlaer et al. 2016), also found URTI to be the most prevalent infection (36\%). These results are in line with the results described in the present study. Low hygiene caused by crowded buses, trains and residing in dense camps were presumably contributing factors (Sharara and Kanj 2014). Future interventions should target this problem by a proper preparation of medicines, sufficient nutrition, and hygiene. Accordingly, the most frequent treatment prescribed included antibiotics and analgesics. The frequent use of antibiotics could be explained by the lack of any follow-up as patients continued on their way and one could not predict the evolvement of their disease. Physical trauma was diagnosed, mainly in men (64\%) probably due to war injuries, including amputations, gunshot wounds, and others. The infrequent reporting of injuries in women could possibly be due to having other priorities (e.g., child-care). 
Psychiatric disorders (e.g., PTSD) were diagnosed in only $0.3 \%$ of patients. This is lower than studies performed in later phases of immigration. Considering post-traumatic stress disorder (PTSD) alone, this figure is $1 / 100$ of the expected prevalence among Syrian refugees (33.5\%) (Alpak et al. 2015). However, our diagnoses were not based on standardized assessments. Patients' priority to reach Northern Europe, and thus possibly underreporting such symptoms, could also explain the low rates of diagnosed psychiatric disorders. Very brief and valid assessment tools exist for such situations (Kimerling et al. 2006). This emphasizes the importance of humanitarian agencies to monitor and treat patients with such disorders in such contexts (Roberts and Hofmann 2004).

The low percentage of women with OBGYN complaints might be due to language and cultural barriers: the medical team included Arabic speakers, but almost no staff speaking languages originating from Afghanistan or some parts of Iraq. The higher percentage of women with abdominal infections in comparison to RTI could partly be explained by misclassified OBGYN problems or by women preferring to report abdominal rather than genital symptoms, possibly due to culture-related stigma.

The low percentage of patients with chronic diseases is not in line with Doocy et al. (2015), who found a $50.3 \%$ of chronic diseases. First, the clinical setting in the present study was primarily for emergency medicine for patients en route, while the study in Jordan included settled refugees. It is also possible that among settled refugees in nearby Jordan, more elderly people lived, while the present sample included mainly young and more mobile people, thus, with low frequency of chronic diseases. Indeed, when observing both Doocy et al. (2015) and Cetorelli et al. (2017), older age was correlated with higher prevalence of NCD.

In contrast to the present study, the incidence of chronic infectious diseases rose in Syria during the last few years (Ozaras et al. 2016a). Chronic infectious diseases (tuberculosis, hepatitis) were probably underdiagnosed in our setting because of lack of diagnostic tools. There is a need to promote early diagnosis for preventing the spread of infection.

This might be a public health-hazard for other refugees as well. Thus, screening for tuberculosis should be encouraged, particularly if the refugees reach an industrialized country (Odone et al. 2014).

Moreover, we found that older age was associated with RTI. The older age groups had higher rates of RTI possibly because infants may have immune protection via breast feeding (Sharara and Kanj 2014; Oddy et al. 2003; Duijts et al. 2009; Ladomenou et al. 2010; Hanson and Korotkova 2002).

We observed under diagnosis of pain in infants and pre-school children relative to adults and to their percentage in the sample, while the opposite occurred in adults. The prevalence of pain as the chief complaint observed among children here is considerably lower than that seen in general practice across ages (e.g., 30\% in Hasselström et al. (2002). Patients under 18 years old were diagnosed in accordance with the location of their pain (e.g., an abdominal disease for abdominal pain), while adults received treatment for pain itself. We recommend that refugee clinical staff devote attention and assess children's pain with validated and costless pain face scales (Moutte et al. 2015).

This study has several limitations. It included a selfselected rather than a random and representative sample. Moreover, the diagnoses were mainly based on clinical rather than on objective tests. Both issues could affect the observed prevalence rates and observed demographic correlates of the diagnoses and treatments. These limitations and others were observed in other similar situations and conditions within the humanitarian context (Blanchet et al. 2017). Nevertheless, this study provides a glimpse into the health status of the migrants arriving in Europe. Further studies are needed to provide a broader perspective that will enable hosting countries to be better prepared for immigrants' health needs, to deal with this crisis from the medical points of view.

Alongside the main findings, we would like to share our experiences with other practitioners who might face similar conditions.

\section{Practical recommendations}

The lack of standardized diagnostic criteria makes the clinical assessment difficult. It is left to the individual professional to arrive at the right conclusion and treat patients appropriately.

When successive volunteers without proper overlapping shift-transferring time are staffing a clinic, there is no unified standard of care. Simple protocols and guidelines should be in place.

The frequency of infections among the patients requires a variety of antibiotics, which again should be used according to clear guidelines. More attention to assessing pain in children and to assessing severe mental health consequences with brief standardized tools are required.

The unbearable time constraints of people rushing through the camp, worrying about missing an opportunity to move on, creates a situation which calls for rapid assessment and provision of simple well-defined treatments, rather than diagnostic workup, hospitalization, and parenteral medications. Under such conditions, reaching out to the masses standing in line and searching for people who need medical help, are warranted rather than only sitting in the clinic, waiting for patients to come.

During hours of massive movement of people through the camp, large numbers of patients overwhelm the clinic. 
Triage and prioritizing by a senior member of the medical team are needed.

More detailed data collection, clinical reasoning, and details about treatment should have been collected in duplicate, with one copy given to the patient to be used further along the route, and the other kept as a permanent record in the clinic.

When medical teams come from different countries, they should not supplement the content of the pharmacy by medications brought form their home country. Local authorities will not allow foreign teams to use medications, which are not available locally. The rationale behind this is the statement that refugees should not receive treatment which is not available to the local population. This will determine the standard of care at the clinic.

\section{Abbreviations}

GIl: Gastrointestinal infections; NGO: Non-governmental organization; OBGYN: Obstetrics and gynecology; PTSD: Post traumatic stress disorder; RTI: Respiratory tract infections; UNHCR: United Nation's High Commission for Refugees

\section{Acknowledgements}

The authors wish to thank NATAN Humanitarian organization and all the patients that took part in this study. Their participation will assist other migrants.

\section{Availability of data and materials}

Our data is available for inspection if required.

\section{Authors' contributions}

Prof. MA and Dr. SS collected the data. Mr. EL assisted in the organization leading to all the data collection. Prof. Y G performed the statistical analysis and all four of authors participated in the write up of the manuscript. All authors read and approved the final manuscript.

\section{Funding}

This study was done as part of humanitarian mission funded by NATAN for international humanitarian aid (NGO).

\section{Competing interests}

All authors declare that they have no competing interests.

\section{Author details}

${ }^{1}$ The Free University of Brussels, (VUB), Brussels, Belgium. ${ }^{2}$ The Israeli School of Humanitarian Aid, Tel Aviv, Israel. ${ }^{3}$ School for International Health, Ben Gurion University, Bersheeba, Israel. ${ }^{4}$ Clalit Health Services, Tel Aviv, Israel. ${ }^{5}$ SCALab, Lille3 University, Villeneuve-d' Ascq, France. ${ }^{6}$ Department of Pharmacology and Pharmacokinetics, VUB, Brussel, Belgium.

Received: 30 May 2017 Accepted: 13 October 2017

Published online: 30 October 2017

\section{References}

Ackerman LK (1997) Health problems of refugees. J Am Board Fam Pract 10(5): $337-348$

Alpak G, Unal A, Bulbul F, Sagaltici E, Bez Y, Altindag A, Dalkilic A, Savas HA (2015) Post-traumatic stress disorder among Syrian refugees in Turkey: a cross-sectional study. Int J Psychiatry Clin Pract 19(1):45-50

Blanchet K, Ramesh A, Frison S, Warren E, Hossain M, Smith J, Knight A, Post N, Lewis C, Woodwork A, Dahab M, Ruby A, Sistenich V, Patnuliano S, Roberts B (2017) Evidence on public health interventions in humanitarian crises. Lancet 27

Bradby H, Humphris R, Newall D, Phillimore J (2015) Public health aspects of migrant health: a review of the evidence on health status for refugees and asylum seekers in the European region. World Health Organization Available from: http://www.diva-portal.org/smash/get/diva2:883004/FULLTEXT01.pdf

Cetorelli V, Burnham G, Shabila N (2017) Prevalence of non-communicable diseases and access to health care and medications among Yazidis and other minority groups displaced by ISIS into the Kurdistan region of Iraq. Confl Heal 11:4

Doocy S, Lyles E, Roberton T, Akhu-Zaheya L, Oweis A, Burnham G (2015) Prevalence and care-seeking for chronic diseases among Syrian refugees in Jordan. BMC Public Health 15(1):1097

Duijts L, Ramadhani MK, Moll HA (2009) Breastfeeding protects against infectious diseases during infancy in industrialized countries. A ystematic review. Matern child nutr 5(3):199-210

Glass R, Nieburg P, Cates W, Davis C, Russbach R, Peel S, Nothdurft H, Turnbull R (1980) Rapid assessment of health status and preventive-medicine needs of newly arrived Kampuchean refugees, Sa Kaeo, Thailand. Lancet 315(8173): $868-872$

Gulacti U, Lok U, Polat H (2017) Emergency department visits of Syrian refugees and the cost of their healthcare. Pathog Glob Health 111(5):219-224

Hanson $L \AA$, Korotkova M. The role of breastfeeding in prevention of neonatal infection. In Seminars in neonatology 2002 Aug 1 (Vol. 7, No. 4, pp. 275-281). WB Saunders

Hasselström J, Liu-Palmgren J, Rasjö-Wrååk G (2002) Prevalence of pain in general practice. Eur J Pain 6(5):375-385

http://data2.unhcr.org/en/situations/mediterranean (cited 2017 March 23) 2018

Humedica.org [internet]. Kaufbeuren: Humedica; @ 2016 [cited 2016 August 16]. Available from: https://www.humedica.org/

Kimerling R, Trafton JA, Nguyen B (2006) Validation of a brief screen for post-traumatic stress disorder with substance use disorder patients. Addict Behav 31(11):2074-2079

Ladomenou F, Moschandreas J, Kafatos A, Tselentis Y, Galanakis E (2010) Protective effect of exclusive breastfeeding against infections during infancy: a prospective study. Arch Dis Child 95(12):1004

Lim JH, Yoon D, Jung G, Joo Kim W, Lee HC (2005) Medical needs of tsunami disaster refugee camps. Fam Med 37(6):422-428

Moutte SD, Brudvik C, Morken T (2015) Physicians' use of pain scale and treatment procedures among children and youth in emergency primary care-a cross sectional study. BMC emerg med 15(1):1

Natan-iha.org [internet]. Israel: NATAN International Humanitarian Aid [cited 2016 August 16] 2018. Available from: http://www.natan-iha.org/

Oddy WH, Sly PD, De Klerk NH, Landau LI, Kendall GE, Holt PG, Stanley FJ (2003) Breast feeding and respiratory morbidity in infancy: a birth cohort study. Arch Dis Child 88(3):224-228

Odone A, Tillmann T, Sandgren A, Williams G, Rechel B, Ingleby D, Noori T, Mladovsky P, McKee M (2014) Tuberculosis among migrant populations in the European Union and the European economic area. The European J Public Health 25(3):506-12.16

Ozaras R, Balkan II, Yemisen M (2016b) Prejudice and reality about infection risk among Syrian refugees. Lancet Infect Dis 16(11):1222-1223

Ozaras R, Leblebicioglu H, Sunbul M, Tabak F, Balkan II, Yemisen (2016a) The Syrian conflict and infectious diseases. Expert Rev Anti Infect Ther 14(6):547-555

Roberts L, Hofmann CA (2004) Assessing the impact of humanitarian assistance in the health sector. Emerg themes in epidemiology 1(1):3

Sharara SL, Kanj SS (2014) War and infectious diseases: challenges of the Syrian civil war. PLoS Pathog 10(11):e1004438

Unhcrie [internet]. Ireland: United Nations High Commission for Refugees; @ 2001-2012 [updated 2016 August; cited 2016 August 16]. Available from: http//mww.unhcr.ie/ resources/resources

van Berlaer G, Carbonell FB, Manantsoa S, de Béthune X, Buyl R, Debacker M, Hubloue I (2016) A refugee camp in the centre of Europe: clinicalCharacteristics of asylum seekers arriving in Brussels. BMJ Open 6(11): e013963 